\title{
Territórios da Cidadania do estado de Mato Grosso: uma avaliação socioeconômica utilizando o índice FIRJAN
}

\author{
Territories of Citizenship of the Mato Grosso state: a socio-economic evaluation using \\ the FIRJAN index
Territoires de la citoyenneté de l'État du Mato Grosso: une évaluation socio-économique en utilisant la FIRJAN d'index \author{
mediante el indice de FIRJAN \\ Henri Cócaro* \\ (henri.cocaro@ifsudestemg.edu.br) \\ Raquel Finamor Cardoso* \\ (raquelfinamor@yahoo.com.br) \\ José Roberto Pereira* \\ (jrobertopereira2013@gmail.com)
}

Territorios de Ciudadanía del estado de Mato Grosso: una evaluación socioeconómica

Recebido em 21/06/2014; revisado e aprovado em 13/08/2015; aceito em 12/10/2015

DOI: http://dx.doi.org/10.20435/1984042X2016204

\begin{abstract}
Resumo: A política pública Territórios da Cidadania busca reduzir a pobreza e a desigualdade social por meio do desenvolvimento territorial sustentável. Este estudo avaliou os indicadores socioeconômicos dos Territórios da Cidadania do estado de Mato Grosso tendo como fonte de dados o Índice Firjan de Desenvolvimento Municipal. Os resultados apontam para um progresso dos indicadores em quase todos os territórios, contudo a maioria dos municípios ainda encontram-se com resultados inferiores ao recorte de 0,650 estipulado como adequado.

Palavras-chave: desenvolvimento territorial; indicadores FIRJAN; políticas públicas e sociais.

Abstract: Public policy Citizenship Territories seeks to reduce poverty and social inequality through sustainable territorial development. This study assessed the socioeconomic indicators of the citizenship territories of the Mato Grosso state as a data source with the Municipal Development Index Firjan. The results indicate an improvement of indicators in almost all areas, however, most municipalities still find yourself with results below the cut of 0,650 set as appropriate.

Key words: territorial development; FIRJAN indicators; public and social policies.

Résumé: La politique publique des Territoires citoyenneté vise à réduire la pauvreté et l'inégalité sociale par le développement territorial durable. Cette étude a évalué les indicateurs socio-économiques des territoires de la citoyenneté de l'État du Mato Grosso comme une source de données avec la Firjan Indice de Développement Municipal. Les résultats indiquent une amélioration des indicateurs dans presque tous les domaines, cependant, la plupart des municipalités encore vous retrouver avec des résultats inférieurs à la coupe de 0,650 définir le cas échéant.

Mots-clés: développement territorial; indicateurs FIRJAN; politiques publiques et sociales.

Resumen: La política pública Territorios de Ciudadanía tiene por objeto reducir la pobreza y la desigualdad social a través del desarrollo territorial sostenible. Este estudio evaluó los indicadores socioeconómicos de los territorios de la ciudadanía del estado de Mato Grosso como una fuente de datos con el Índice de Desarrollo Municipal Firjan. Los resultados indican una mejora de los indicadores en casi todas las áreas, sin embargo, la mayoría de los municipios todavía se encuentra con resultados por debajo de la cortede 0,650 establecido como apropiado.

Palabras clave: desarrollo territorial; indicadores FIRJAN; políticas públicas y sociales.
\end{abstract}

\section{INTRODUÇÃO}

A industrialização e o desenvolvimento nos estados brasileiros transcorreram por rotas de desigualdades intrínsecas, tornando-se preocupações permanentes dos organismos governamentais que buscam integrar e gerir políticas públicas que promovam o desen- volvimento econômico sustentável local. A abordagem de programas territoriais surge nesse contexto, articulando uma nova forma de arranjo que aglomera e organiza os municípios territorialmente com certo grau de homogeneidade dentro de um mesmo Estado, visando diminuir as fronteiras restritivas e alavancar as potencialidades através da inten-

* Universidade de Lavras (UFLA), Lavras, Minas Gerais, Brasil. 
sificação de ações que conduzam a promoção e a garantia do bem-estar social. Nesse intuito, o Governo Federal lançou, em 2008, a política pública "Territórios da Cidadania", que busca desenvolver os direitos sociais pautado na participação social e na integração de ações envolvendo municípios e estados.

A análise das diretrizes dessa política pública retrata um claro exemplo da tutela exercida pelo Estado acerca dos direitos dos indivíduos que vivem em determinado território. Assim, pressupõe-se que essa política, ao reconhecer a pluralidade das diferenças regionais e trabalhar arduamente para promover e atender as necessidades básicas da população, se encontra intrinsecamente ligada a um dos pilares da cidadania: os direitos sociais. Esses direitos compreendem o gerenciamento eficaz e eficiente da saúde, educação, remuneração digna, aposentadoria, mercado de trabalho, dentre outros que fornecem subsídios para se reduzir a desigualdade social e econômica.

Como recorte geográfico para analisar o desenvolvimento territorial, optou-se pelo Estado de Mato Grosso, que possui aproximadamente $903.329,700 \mathrm{Km}^{2}$ de extensão, uma população estimada em 2013 de 3.182.113 habitantes e 141 municípios (IBGE, s.d.), sendo um significante expoente no cenário agrícola tanto pelas condições de clima e solo que facilitam a exploração de commodities, como pela considerável inserção de incentivos concedidos pelo governo do estado. Essas condições têm contribuído para a migração de muitos cidadãos em direção às regiões Norte e Sul, onde se concentram as maiores indústrias, assim como as grandes plantações de grãos. Essa atração de grandes indústrias e agricultores de uma forma geral, tem propiciado o crescimento econômico regional e garantido ao estado o maior PIB agropecuário do país (PEREIRA, 2007).

Entretanto o crescimento expressivo da economia, comumente representado pelo PIB, nem sempre representa desenvolvimento econômico. O desenvolvimento econômico é um conceito mais qualitativo, incluindo alterações da composição do produto e a alocação dos recursos pelos diferentes setores da economia, de forma a melhorar os indicadores de bem-estar econômico e social (pobreza, desemprego, desigualdade, condições de saúde, alimentação, educação e moradia) da população (VASCONCELOS, 2000).

É com base nesse contexto, sinteticamente apresentado, que se propõe responder à seguinte questão norteadora deste estudo: as ações públicas realizadas nos Territórios da Cidadania estão promovendo o desenvolvimento local? Para responder ao questionamento proposto, estabeleceu-se como objetivo geral deste trabalho verificar os avanços e/ ou retrocessos nas condições de qualidade de vida das populações de cada Território da Cidadania do estado de Mato Grosso. Para isso foram utilizados os seguintes indicadores socioeconômicos referentes ao período 2005 a 2011: Emprego e Renda; Educação; Saúde. Para embasar estas reflexões o artigo está estruturado da seguinte forma: inicialmente, é apresentado o referencial teórico que aborda as relações entre reforma do Estado, Políticas Públicas e Sociais; posteriormente, realiza-se uma breve contextualização a respeito do programa Territórios da Cidadania e da metodologia embasada na utilização do Índice Firjan de Desenvolvimento Municipal (IFDM); na sequência, apresentam-se os resultados e discussões e encerra-se com as considerações finais.

\section{REFORMA DO ESTADO}

Segundo Pereira (2010a, p. 113), no percurso do Estado moderno, duas reformas administrativas se destacaram: "reforma burocrática: [...] trata-se do processo de transição do Estado patrimonial para o Estado burocrático weberiano; [e] reforma da gestão pública: orienta a transição do Estado burocrático para o Estado gerencial".

Para J. R. Pereira (2010) os tipos de administração pública podem ser localizados no tempo e no espaço em diferentes lugares do mundo. Historicamente, pode-se considerar a existência de três tipos básicos de administração pública ou três formas de administrar o Estado: Administração Patrimonialista, Administração Burocrática; Administração Gerencial.

Conforme Bresser-Pereira (2010), patrimonialismo significa a incapacidade ou relutância de o príncipe distinguir entre o patrimônio público e seus bens privados. Nesse sentido, podem-se considerar algu- 
mas características básicas ressaltadas por Campante (2003), quais sejam: caráter personalista do poder; ausência de uma esfera pública contraposta à privada; lógica subjetiva e casuística do sistema jurídico, irracionalidade fiscal; tendência à corrupção do quadro administrativo; relações de lealdade pessoal; ausência de limites entre os bens e recursos públicos e privados; clientelismo, corrupção e nepotismo; a função do Estado e do serviço público é dar emprego e favorecer aliados.

Por outro lado, a administração pública burocrática apresenta as seguintes características básicas: distribuição de atividades e poderes que visa à execução regular e contínua de certos fins; hierarquia de cargos e instâncias que ordena o sistema de mando e subordinação; registros sob a forma de documentos escritos; administração dos funcionários segundo regras que podem ser aprendidas; impessoalidade nas relações entre as pessoas (WEBER, 1999). Sua introdução em vários países, inclusive no Brasil, teve a finalidade de superar as mazelas do patrimonialismo, no sentido de acabar ou minimizar as práticas clientelísticas. Porém, no Brasil, o modelo burocrático tradicional funcionou de forma limitada, sem dar conta da superação do patrimonialismo e reforçou traços de autoritarismo nos cargos públicos, por meio da hierarquia e do controle, viabilizando o poder de uma elite burocrática (ABRUCIO, 2007), aspectos que estão relacionados com a nossa formação histórica, como ressalta Costa (2006).

Os grandes intérpretes da realidade brasileira têm salientado que as raízes do nosso atraso, subdesenvolvimento, dependência, modernização periférica ou inserção pouco competitiva no mundo globalizado estão plantadas na formação histórica brasileira, gerando uma série de determinantes que condicionam o sistema político, o Estado e suas relações com a sociedade e a economia. Essas peculiaridades constituem modo de ser, proceder ou pensar que caracterizam nossas instituições, relações sociais e representantes do mundo social e político. (COSTA, 2006, p. 140).

No sentido de superar os entraves burocráticos e patrimonialistas da gestão pública, Cardoso (2005, p. 17) enfatiza “[...] preparar a nossa administração para a superação dos modelos burocráticos do passado, de forma a incorporar técnicas gerenciais que introduzam na cultura do trabalho público as noções indispensáveis de qualidade, produtividade, resultados, responsabilidade dos funcionários, entre outras". Nessa mesma linha de raciocínio, Przeworski (2005, p. 40) considera que "assim, a tarefa de reformar o Estado consiste, por um lado, em equipá-lo com instrumentos para uma intervenção efetiva e, por outro, em criar incentivos para que os funcionários públicos atuem de modo a satisfazer o interesse público".

O resultado dos esforços de superação do patrimonialismo e das mazelas burocráticas foi a emergência da administração pública gerencial ou nova gestão pública, que se fundamenta em valores de eficiência, eficácia e competitividade. Para Osborne e Gaebler (1995), o governo, nesse cenário, é tido como: catalisador, pertencente à comunidade, competitivo, orientado para missões, de resultados, para clientes, empreendedor, preventivo, descentralizado, orientado para o mercado e reinventado.

Essa nova fase de institucionalização da gestão pública se encontra, fundamentalmente, vinculada à eficiência administrativa e no foco no cidadão beneficiário dos serviços públicos. Para Paes de Paula (2005), entre as bases teóricas da nova Administração Pública, está o pensamento neoliberal, no qual o Estado deveria ser estruturado para cumprir, basicamente, quatro objetivos: proteger os cidadãos dos potenciais inimigos; garantir que cada cidadão seja autossuficiente para seu desenvolvimento; manter uma estrutura que possibilite uma competição e uma cooperação eficientes entre os homens, viabilizando o bom funcionamento do livre-mercado; e criar um ambiente seguro para os cidadãos, garantindo não a igualdade material, mas as condições de competição, ou seja, o acesso aos recursos de que todos necessitam para competir. Ainda, segundo Paes de Paula (2005), o neoliberalismo se espalhou propondo respostas à crise do Estado de Bem Estar Social. No entanto o neoliberalismo foi fortemente criticado no início dos anos 90, década na qual surgiram novas tendências políticas como a "Terceira Via" proposta por Anthony Giddens, e que influenciou a reforma do Estado no Brasil. 
A política de Terceira Via é uma corrente que surgiu com o objetivo auxiliar os cidadãos a desbravar caminhos por meio das mais importantes revoluções que envolviam a globalização, transformações na vida pessoal e o relacionamento com a natureza. Giddens (2001) sugere alguns valores que compõem a política de Terceira Via como: igualdade, proteção aos vulneráveis, liberdade como autonomia, na qual não há direitos sem responsabilidades e não há autoridade sem democracia.

Assim, a nova proposta política baseia-se na integração entre o setor público e o setor privado ao justificar a dinâmica do mercado com o propósito de um bem-estar social. Para Giddens (2001), a reforma do Estado deveria ser um princípio orientador básico da política de Terceira Via, um processo de aprofundamento e ampliação da democracia. Considera que o governo pode agir em parceria com instituições da sociedade civil para fomentar a renovação e o desenvolvimento da comunidade, cuja base econômica é defendida pelo autor como "a nova economia mista". Para ele, se, por um lado, os neoliberais querem encolher o Estado, por outro, os socialistas buscam expandi-lo, e a Terceira Via se propõe a reconstruí-lo.

Todavia há um vazio entre a reforma do Estado no Brasil e a participação cívica da população nos espaços públicos. É nesse ambiente em que gestão social adquire grande relevância, pois esta busca um gerenciamento participativo e dialógico, envolvendo diferentes sujeitos sociais no processo decisório da ação pública (TENÓRIO, 2007). Ainda conforme esse autor, a ação dialógica desenvolve-se segundo pressupostos do agir comunicativo, ou seja, agrega o acordo alcançado por meio da discussão crítica e da apreciação intersubjetiva. O conceito elaborado por Tenório (2007) está alinhado ao pensamento de Habermas (2003), principalmente, com base no conceito de cidadania deliberativa e na Teoria da Ação Comunicativa. Para Habermas (2003), a esfera pública é "um princípio organizacional de nosso ordenamento político", na qual se destaca o Estado como "poder público" pela tarefa que assume de promover o bem público, o bem comum a todos os cidadãos. Para Gohn (2004, p. 77-8):

O fato de a esfera pública ser um espaço de relações sociopolíticas e culturais implica que ela é também um espaço de explicitação de interesses - que podem ser similares ou contrastantes, envolvendo, portanto, interesses consensuais e/ou em conflito; um espaço de confronto, embates, criação de consensos e de alianças entre projetos sociopolíticos diferenciados, segundo as matrizes valorativas/culturais dos grupos de interesses que eles representam; para se chegar a um consenso, há negociações variadas envolvendo estratégias políticas, busca de reconhecimento, culturas e práticas político/valorativas, disputas pela direção e hegemonia dos coletivos etc.

Assim, a política pública Territórios da Cidadania, ao sinalizar a adoção da gestão social no seu processo de operacionalização nos territórios, busca superar o "vazio" entre a ação do Estado e a participação da sociedade.

\section{POLÍTICAS PÚBLICAS DE DESENVOLVIMENTO TERRITORIAL E TERRITÓRIOS DA CIDADANIA}

Em termos gerais, política pública significa o Estado em ação. Nesse sentido, Muñoz Amato (1971, p. 9) analisa:

Em todo caso, a realização da política pública, dos objetivos do Estado, é a tarefa que na realidade executam conjuntamente os cidadãos, os partidos políticos, as associações, os parlamentos, ou tribunais, os órgãos da opinião pública, os grupos de interesses econômicos, os funcionários do Poder Executivo e outros agentes. (grifo do autor).

Por outro lado, em se tratando de políticas públicas de desenvolvimento territorial, Alcântara Filho, Silva e Silva (2009, p. 262) consideram que "o desafio fundamental das políticas públicas de desenvolvimento territorial é melhorar as capacidades produtivas e as condições de acesso aos mercados dos empreendedores de pequeno porte".

Desse modo, a abordagem territorial ultrapassa a escala dos municípios, envolve as relações entre Estado e Sociedade intermediada pela participação ativa da esfera pública. Nesse sentido, Rolnik e Somekh (2003, p. 96) lembram que "[...] dificilmente uma cidade 
isoladamente tem força política para determinar a estratégia de investimento e gestão dessas infraestruturas". E complementando, Oliveira, Guimarães Júnior e Pereira (2010, p. 221) consideram que:

[...] a ideia de políticas públicas associa-se a um conjunto de ações articuladas com recursos próprios (especialmente financeiros, mas podendo também incluir humanos), numa dimensão temporal (duração) e com alguma capacidade de impacto. Ela não pode ser reduzida à implantação de serviços, pois engloba projetos de natureza ética e política, além da compreensão de níveis diversos de relações entre o Estado e a sociedade civil na sua constituição.

A partir dessa premissa, Pereira (2010b, p. 210) esclarece que políticas sociais são "[...] as ações que determinam o padrão de proteção social implementado pelo Estado, voltadas, em princípio, para a redistribuição dos benefícios sociais visando á diminuição das desigualdades sociais estruturais produzidas pelo desenvolvimento socioeconômico", na outra ponta está Faleiros (1991, p. 59) cujo entendimento sobre política social

[...] é uma gestão estatal da força de trabalho, articulando as pressões e movimentos sociais dos trabalhadores com as formas de reprodução exigidas pela valorização do capital e pela manutenção da ordem social.

Para esclarecer tais (des)entendimentos sobre políticas sociais, recorre-se a Demo (2010, p. 31), que destaca três horizontes nesse campo: políticas assistenciais, que não devem ser confundidas com o assistencialismo, pois "[...] enquanto o assistencialismo é estratégia de manutenção das desigualdades sociais, a assistência corresponde a um direito humano." Em um segundo horizonte, destacam-se as políticas socioeconômicas, tais como: políticas de emprego, de apoio às formas de microprodução, de profissionalização, habitação, saúde, previdência, transporte, urbanização, de fundos sociais. Por último, as políticas participativas que agregam as políticas educacionais, culturais, comunicação, de defesa da cidadania, conquista de direitos, organização da sociedade civil, partidárias, sindicais, de justiça e de segurança pública (DEMO, 2010).
A abordagem territorial tem ganhado espaço na gestão de políticas públicas sociais nos estados brasileiros, pois tal abordagem prioriza ações que estimulam os processos de desenvolvimento local sustentável, envolvendo municípios e regiões, bem como focaliza a aplicação dos direitos sociais garantidos pela Constituição Federal de 1988. Para Favareto (2010, p. 208):

O foco no Território permite compreender a unidade complexa constituída pelos espaços urbano e rural e pelos âmbitos municipal e supramunicipal. Ela favorece a emergência de temas relacionados com pobreza, desigualdade social, meio ambiente e outras questões que passam a ser tratados com uma ótica de desenvolvimento rural (antes, desenvolvimento rural era sinônimo de desenvolvimento da produção agrícola).

Assim, as políticas públicas territoriais têm favorecido a solidariedade e a cooperação com a diversidade de atores sociais, melhorado a articulação dos serviços públicos, organizando melhor o acesso ao mercado interno, além de contribuir para a construção de uma identidade própria que forneça uma sólida base para a coesão social territorial, verdadeiros alicerces para o exercício da cidadania.

A política pública Territórios da Cidadania é parte do esforço conjunto do Governo Federal, por meio do Ministério do Desenvolvimento Agrário (MDA), em parceria com municípios, estados e a sociedade civil, com objetivo de superar a pobreza e as desigualdades sociais através do desenvolvimento territorial sustentável. Essa política busca, a partir do planejamento territorial, a integração das diversas ações públicas voltadas para a cidadania. As linhas de ação da política são três: a primeira, de apoio à atividade produtiva, focada em ações públicas voltadas à geração de renda e inclusão social na atividade produtiva de acordo com a potencialidade do território. A segunda linha de ação refere-se ao acesso aos direitos e fortalecimento de apoio institucional que visa assegurar a condição básica de cidadania às populações dos territórios delimitados pela política. A última linha de ação é de qualificação da infraestrutura.

Essa política pública é gerida pelos comitês de gestão nacional, articulação esta- 
dual e por um colegiado territorial. O comitê gestor nacional é composto por Secretários Executivos ou Secretários Nacionais de todos os Ministérios, tendo as seguintes atribuições: aprovar diretrizes; organizar as ações federais; adotar medidas para execução e avaliação do programa; mobilizar atores federativos (Pacto Federativo); definir novos territórios. O comitê de articulação estadual é de caráter consultivo e propositivo tendo como atribuições: apoiar a organização e mobilização dos Colegiados; apresentar e/ ou articular ações; acompanhar a execução; fomentar a integração das diversas políticas públicas nos territórios; apresentar sugestões de novos territórios; auxiliar na divulgação do Programa. O colegiado territorial é composto por representantes das três esferas de governo e da sociedade em cada território, tendo como atribuições: elaborar ou aperfeiçoar o Plano de Desenvolvimento do Território; promover a interação entre gestores públicos e conselhos setoriais; contribuir para qualificação e integração de ações; ajudar na execução das ações e identificar ações para serem priorizadas no atendimento; exercer o controle social; dar ampla divulgação sobre as ações do programa (PORTAL DA CIDADANIA, s.d.).

No estado de Mato Grosso, foram criados quatro territórios, sendo eles: Baixada Cuiabana; Baixo Araguaia; Noroeste e Portal da Amazônia (SISTEMA DE INFORMAÇÕES TERRITORIAIS [SIT], 2009). O Território da Cidadania Baixada Cuiabana abrange uma área de $85.369,70 \mathrm{Km}^{2}$ e é composto por 14 municípios ${ }^{1}$. A população total do território é de 976.064 habitantes, dos quais 77.147 vivem na área rural, o que corresponde a 7,90\% do total. Possui 10.260 agricultores familiares, 11.154 famílias assentadas, 49 comunidades quilombolas e quatro terras indígenas. O Território da Cidadania Baixo Araguaia abrange uma área de $116.040,30 \mathrm{Km}^{2}$ e é composto por 15 municípios $^{2}$ (Confresa, Luciára,

\footnotetext{
${ }^{1}$ Municípios que compõem o Território da Baixada Cuiabana: Acorizal, Barão de Melgaço, Campo Verde, Chapada dos Guimarães, Cuiabá, Jangada, Nobres, Nossa Senhora do Livramento, Nova Brasilândia, Poconé, Rosário Oeste, Santo Antônio do Leverger, Várzea Grande e Planalto da Serra.

${ }^{2}$ Municípios que compõem o Território Baixo Araguaia: Confresa, Luciára, Porto Alegre do Norte, Querência, Ribeirão Cascalheira, Santa Terezinha, São Félix do Araguaia, São José do Xingu, Alto Boa Vista, Canabrava do Norte, Novo Santo Antônio, Santa Cruz do Xingu, Serra Nova Dourada, Vila Rica e Bom Jesus do Araguaia.
}

Porto Alegre do Norte, Querência, Ribeirão Cascalheira, Santa Terezinha, São Félix do Araguaia, São José do Xingu, Alto Boa Vista, Canabrava do Norte, Novo Santo Antônio, Santa Cruz do Xingu, Serra Nova Dourada, Vila Rica e Bom Jesus do Araguaia). A população total do território é de 125.127 habitantes, dos quais 51.355 vivem na área rural, o que corresponde a $41.04 \%$ do total. Possui 7.387 agricultores familiares, 16.271 famílias assentadas e 11 terras indígenas. O Território da Cidadania do Noroeste abrange uma área de $149.223,50 \mathrm{Km}^{2}$ e é composto por 7 municí$\operatorname{pios}^{3}$ (Aripuanã, Juína, Juruena, Rondolândia, Castanheira, Cotriguaçu e Colniza). A população total do território é de 122.256 habitantes, dos quais 44.798 vivem na área rural, o que corresponde a 36,64\% do total. Possui 9.692 agricultores familiares, 6.416 famílias assentadas e 10 terras indígenas. O Território da Cidadania Portal da Amazônia abrange uma área de 111.167,50 Km² e é composto por 16 municípios $^{4}$ (Alta Floresta, Apiacás, Carlinda, Colíder, Guarantã do Norte, Marcelândia, Matupá, Nova Bandeirantes, Nova Canaã do Norte, Nova Guarita, Nova Monte verde, Novo Mundo, Paranaíta, Peixoto de Azevedo, Terra Nova do Norte e Nova Santa Helena). A população total do território é de 258.013 habitantes, dos quais 85.035 vivem na área rural, o que corresponde a $32,96 \%$ do total. Possui 20.062 agricultores familiares, 20.647 famílias assentadas e 14 terras indígenas (PORTAL DA CIDADANIA, s.d.).

As ações nos territórios são organizadas em três eixos (apoio a atividades produtivas; cidadania e direitos, infraestrutura) e sete temas (direitos e desenvolvimento social; organização sustentável da produção; saúde, saneamento e acesso à água; educação e cultura; infraestrutura; apoio à gestão territorial; e ações fundiárias).

\footnotetext{
${ }^{3}$ Municípios que compõem o Território Noroeste: Aripuanã, Juína, Juruena, Rondolândia, Castanheira, Cotriguaçu e Colniza.

${ }^{4}$ Municípios que compõem Território Portal da Amazônia: Alta Floresta, Apiacás, Carlinda, Colíder, Guarantã do Norte, Marcelândia, Matupá, Nova Bandeirantes, Nova Canaã do Norte, Nova Guarita, Nova Monte verde, Novo Mundo, Paranaíta, Peixoto de Azevedo, Terra Nova do Norte e Nova Santa Helena.
} 


\section{ASPECTOS METODOLÓGICOS}

Para a avaliação do desenvolvimento nos Territórios da Cidadania do estado de Mato Grosso, foi utilizado o seguinte indicador: Índice Firjan de Desenvolvimento Municipal (IFDM), desdobrado nas áreas de Emprego e Renda, Educação e Saúde.

$O$ IFDM originou-se da necessidade de se monitorar, periodicamente, as potencialidades de desenvolvimento socioeconômico de uma dada região, considerando as diferentes realidades de sua menor divisão federativa, o município.

De acordo com o Ministério das Cidades citado na nota metodológica de Firjan (2008), foram identificados no Brasil mais de 45 Sistemas de Índices Sintéticos abrangendo 816 indicadores sobre 25 temas diferentes. Apesar dessa diversidade de indicadores de desenvolvimento já propostos, algumas limitações podem ser evidenciadas, tais como: complexidade de cálculo, baixa periodicidade e dificuldades na obtenção de dados de entrada. O Índice de Desenvolvimento Humano Municipal (IDH-M), utilizado pela Organização das Nações Unidas, configura-se como o mais bem sucedido. Apesar do seu uso difundido, o IDH-M é resultado de dados censitários disponíveis somente de dez em dez anos, assim o IFDM apresenta as seguintes vantagens em relação ao IDH-M:

- O IFDM é anual, enquanto o IDH-M é censitário. Desta forma, com o IFDM é possível ver o filme ao invés de fotos esparsas a cada dez anos do IDH-M. Assim, ganha-se além da aferição, uma ferramenta de gestão pública.

- O IFDM permite tanto a comparação relativa quanto absoluta entre municípios ao longo do tempo, uma vez que sua metodologia permite especificar se uma melhora relativa deveu-se a fatores específicos do município em questão ou à piora dos demais. O IDH-M não permite a comparação ao longo do tempo, na medida em que as notas de corte são determinadas pela amostra do ano em questão.

- O IFDM foi desenvolvido diretamente para avaliar o desenvolvimento dos municípios, com variáveis que espelham com maior nitidez a realidade municipal brasileira. $\mathrm{O}$ IDH-M, sendo uma adaptação do IDH desenvolvido para analisar os mais diferentes paí- ses, é mais limitado para analisar a realidade municipal do ponto de vista metodológico. Assim, o IFDM traz uma visão mais atualizada com melhor utilização do conjunto de indicadores brasileiros em sua composição.

O IFDM abrange, com igual ponderação, as três principais áreas de desenvolvimento humano: Emprego e Renda, Educação e Saúde (Figura 1).

Figura 1 - Resumo dos índices componentes do IFDM por área de desenvolvimento

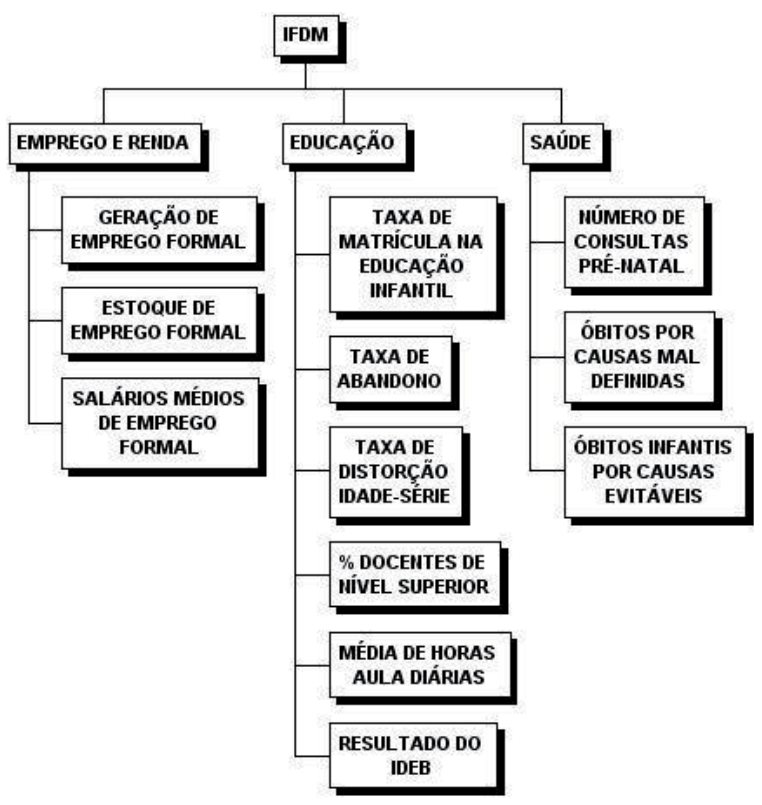

Fonte: FIRJAN - IFDM. Nota metodológica (2009).

Pressupõe-se que as bases de dados geradas pelo IFDM para estas três áreas (Emprego e Renda, Educação e Saúde) constituem um mecanismo colaborador para a gestão de políticas públicas por ter periodicidade anual, recorte municipal e abrangência nacional, bem como estarem disponíveis publicamente nos sites oficiais do governo, permitindo aos gestores dados e informações bem próximas e atuais da realidade vivenciada em cada município.

A metodologia deste estudo está fundamentada na análise quantitativa de dados secundários obtidos em publicações do IBGE e FIRJAN. Para aplicação do índice FIRJAN aos Territórios da Cidadania do Mato Grosso, utilizou-se estatística descritiva simplificada objetivando-se o cálculo de médias de cada território e variação percentual dos índices de 2005 a 2007, 2007 a 2009; e 2009 a 2011. Os seguintes passos nortearam a elaboração dos 
gráficos: 1) Levantamento dos Territórios da Cidadania que existem no estado de Mato Grosso; 2) Identificação e agrupamento dos municípios que compõem cada território; 3 ) Pesquisa do IFDM de cada um dos municípios para os anos 2005, 2007, 2009; 2011; 4) Determinação das médias do IFDM-Geral e das médias do IFDM de cada área de desenvolvimento (Emprego e Renda; Educação; Saúde) para cada território para os anos 2005, 2007, 2009, 2011; 5) Comparação das médias e cálculo da sua variação percentual do ano de 2005 para 2007, do ano de 2007 para 2009; e do ano de 2009 para 2011; 6) Classificação da condição de desenvolvimento para cada Território e para cada área de desenvolvimento.

Sabe-se que, segundo a metodologia de leitura dos resultados do IFDM, tanto as áreas de desenvolvimento como do índice final, variam entre 0 e 1 , e quanto mais próximo de 1 , maior o nível de desenvolvimento da localidade. De acordo com a metodologia, são quatro classificações da condição de desenvolvimento que podem ser encontradas: "Alto Desenvolvimento" (IFDM situado acima de 0,800); “Desenvolvimento Moderado" (IFDM situado entre 0,600 e 0,800); "Desenvolvimento Regular" (IFDM situado entre 0,400 e 0,600) e; "Baixo Desenvolvimento" (IFDM situado abaixo de 0,400). Essa classificação também é utilizada para classificar um município de acordo com cada área de desenvolvimento (Emprego e Renda; Educação; e Saúde).

No recorte analítico deste trabalho, propôs-se uma linha de corte no valor 0,650 para a interpretação dos resultados e discussões, $\mathrm{o}$ qual representa as condições mínimas a serem atingidas por qualquer município que busca desenvolver-se e não apenas crescer economicamente. A escolha do valor 0,650 situa-se como aceitável já que foi a média nacional de todos os municípios do país, apurada em 2011 foi de 0,630.

\section{PERSPECTIVAS DOS TERRITÓRIOS DA CIDADANIA NO ESTADO DE MATO GROSSO}

Nesta seção, busca-se responder se as ações públicas realizadas nos quatro Territórios da Cidadania no estado de Mato Grosso, (Baixada Cuiabana; Baixo Araguaia; Portal da Amazônia e Noroeste) estão contribuindo para o desenvolvimento local tendo como base para as análises e discussões, os indicadores do IFDM, cujos resultados serão apresentados e discutidos a seguir. Nesse sentido, Sá Pestana (2009, p. 62) relata que:

Mas avaliar só para constatar uma re-
alidade não é avaliar, é preciso medir,
é levantar dados. E dados são úteis
quando convertem em informações,
ou seja, significam uma qualificação
que permite o diagnóstico de uma
dada situação e orientação da ação,
trazendo, assim, a possibilidade de
correção das deficiências, por meio
da eliminação ou modificação de
processos ou produtos indesejáveis.

A partir dos resultados encontrados do IFDM-Emprego e Renda para cada município pertencente ao seu respectivo território, realizou-se o agrupamento deles e, posteriormente, o cálculo da média, apresentada no Gráfico 1. 
Gráfico 1 - Médias anuais do IFDM-Emprego e Renda dos Territórios da Cidadania do estado de Mato Grosso

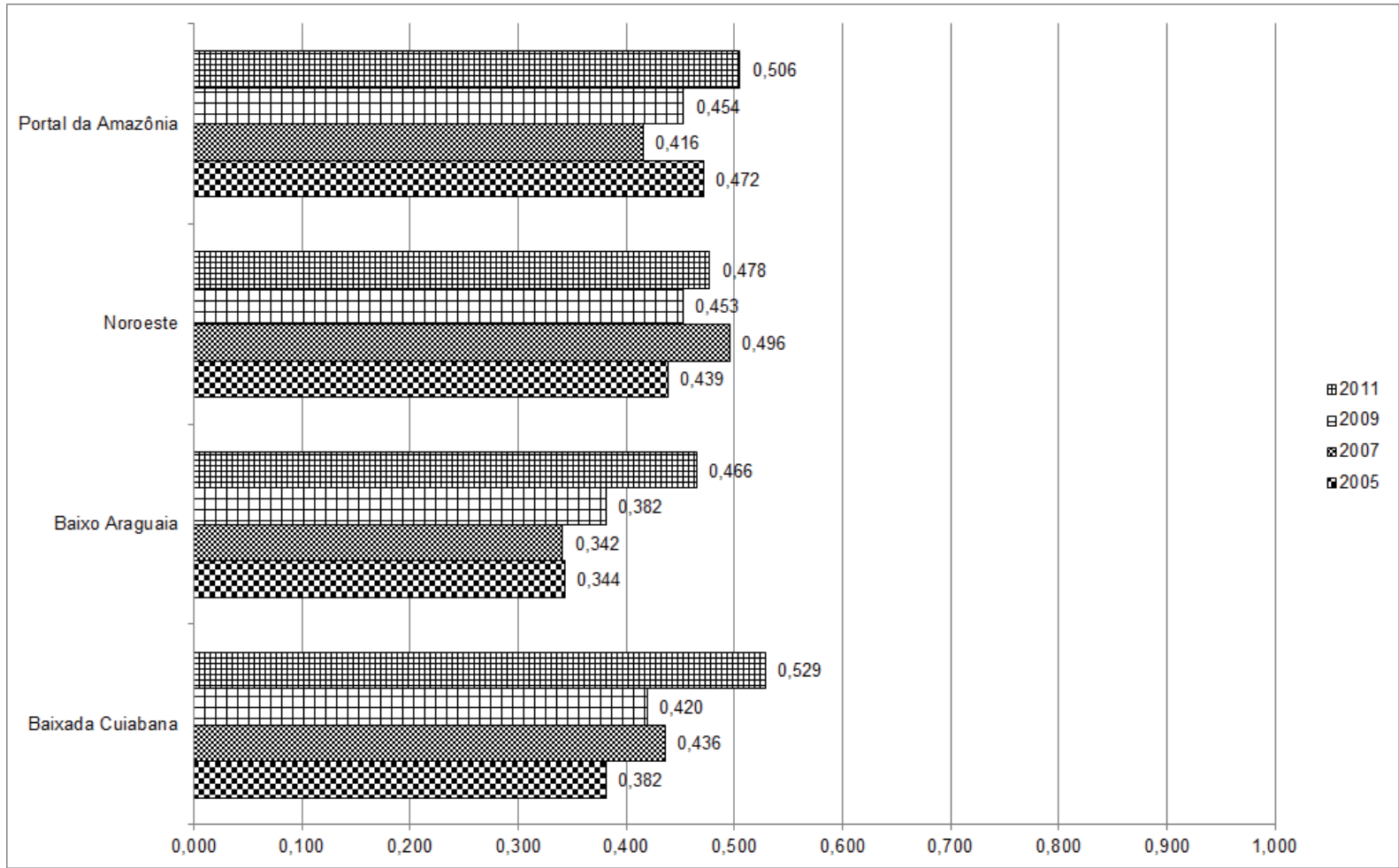

Fonte: Adaptado de FIRJAN - IFDM (2014).

Desse modo, percebe-se que as médias do IFDM-Emprego e Renda de todos os territórios encontraram-se com valores muito inferiores à linha de corte de 0,650 , apontando dificuldades na oferta de condições mínimas para desenvolver-se. O Território do Baixo Araguaia é o que apresenta os piores resultados desde 2005. Destaca-se que, entre os anos de 2005 e 2011, todos os territórios tiveram melhoras em seus resultados. Comparando um período com outro, a média de todos foi superior à média inicial, resultado que indica uma interferência positiva nas dimensões emprego formal e salário médio.

A análise da condição de desenvolvimento utilizando a média anual do IFDM-Emprego e Renda apontou que, em todo o período de análise, de 2005 a 2011, os Territórios Noroeste e Portal da Amazônia foram classificados como de “Desenvolvimento Regular". No ano de 2005, o Território Baixada Cuiabana apresentou a condição de "Baixo Desenvolvimento", porém, nos anos subsequentes, galgou a condição de "Desenvolvimento Moderado" mantendo-a até 2011. Já o Território Baixo Araguaia manteve-se na condição de "Baixo Desenvolvimento" de 2005 a 2009 e, em 2011, passou para a condição de "Desenvolvimento Regular"

Os dados também demonstraram grande oscilação das médias do IFDM-Emprego e Renda nos territórios para os períodos analisados conforme apresentado na Tabela 1. 
Tabela 1 - Variação percentual das médias do IFDM-Emprego e Renda dos Territórios da Cidadania do estado de Mato Grosso

\begin{tabular}{|l|c|c|c|c|}
\hline \multicolumn{1}{|c|}{ TERRITÓRIOS } & $\mathbf{2 0 0 5 - 2 0 0 7}$ & $\mathbf{2 0 0 7 - 2 0 0 9}$ & $\mathbf{2 0 0 9 - 2 0 1 1}$ & Acumulado 2005-2011 \\
\hline Baixada Cuiabana & $14,2 \%$ & $-3,7 \%$ & $25,9 \%$ & $36,4 \%$ \\
\hline Baixo Araguaia & $-0,7 \%$ & $11,7 \%$ & $21,9 \%$ & $33,0 \%$ \\
\hline Noroeste & $13,0 \%$ & $-8,7 \%$ & $10,2 \%$ & $14,5 \%$ \\
\hline Portal da Amazônia & $-11,8 \%$ & $9,0 \%$ & $11,5 \%$ & $8,7 \%$ \\
\hline
\end{tabular}

Fonte: Adaptado de FIRJAN - IFDM (2014).

Nota-se que a variação percentual das médias do IFDM-Emprego e Renda, complementa as informações relatadas no Gráfico 1. Assim, percebe-se que as melhoras relevantes em cada período ocorreram nos Territórios Baixada Cuiabana (14,2\%) e Noroeste de 20052007 (13,0\%), Baixo Araguaia (11,7\%) e Portal da Amazônia (9,0\%) de 2007 a 2009, seguido dos Territórios da Baixada Cuiabana (25,9\%) e Baixo Araguaia (21,9\%) no período de 2009 a 2011. Também destaca-se que tanto o Território Baixada Cuiabana quanto o Baixo Araguaia foram os que mais melhoraram os seus índices no decorrer dos anos, comprovado pelo acumulado 2005 a 2011. Assim, percebe-se que, na avaliação do conjunto, todos os territórios tiveram alternâncias entre quedas e elevações do índice, porém com resultado positivo no acumulado de todo o período (2005 a 2011).

A geração de emprego e renda é fundamental para o desenvolvimento, pois, conforme descrito por Green (2009, p. 177), "gerar empregos em número suficiente e com a qualidade necessária é um dos principais desafios do desenvolvimento", além disso, ainda segundo Green (2009, p. 166), “sem uma renda estável ou acesso à proteção social, os trabalhadores, particularmente mulheres trabalhadoras, ficam presos na pobreza e são vulneráveis a choques".

Obviamente só esta não é suficiente para melhoria das condições de vida, sendo a educação outro importante setor a ser analisado. Conforme Silva, Silva e Rosa (2009, p. 262), "a educação constitui uma dimensão central para ampliar as chances de uma inclusão promissora no mercado de trabalho." Para Sá Pestana (2009, p. 56):

A educação é, hoje, requisito tanto para o pleno exercício da cidadania como para o desempenho de atividades cotidianas, para a inserção qualificada no mercado de trabalho e para o desenvolvimento econômico é, também, elemento essencial para tornar a sociedade mais justa, solidária e integrada.

No Gráfico 2, apresenta-se a média do IFDM-Educação para os Territórios da Cidadania do Estado de Mato Grosso: 
Gráfico 2 - Médias anuais do IFDM-Educação dos Territórios da Cidadania do estado de Mato Grosso

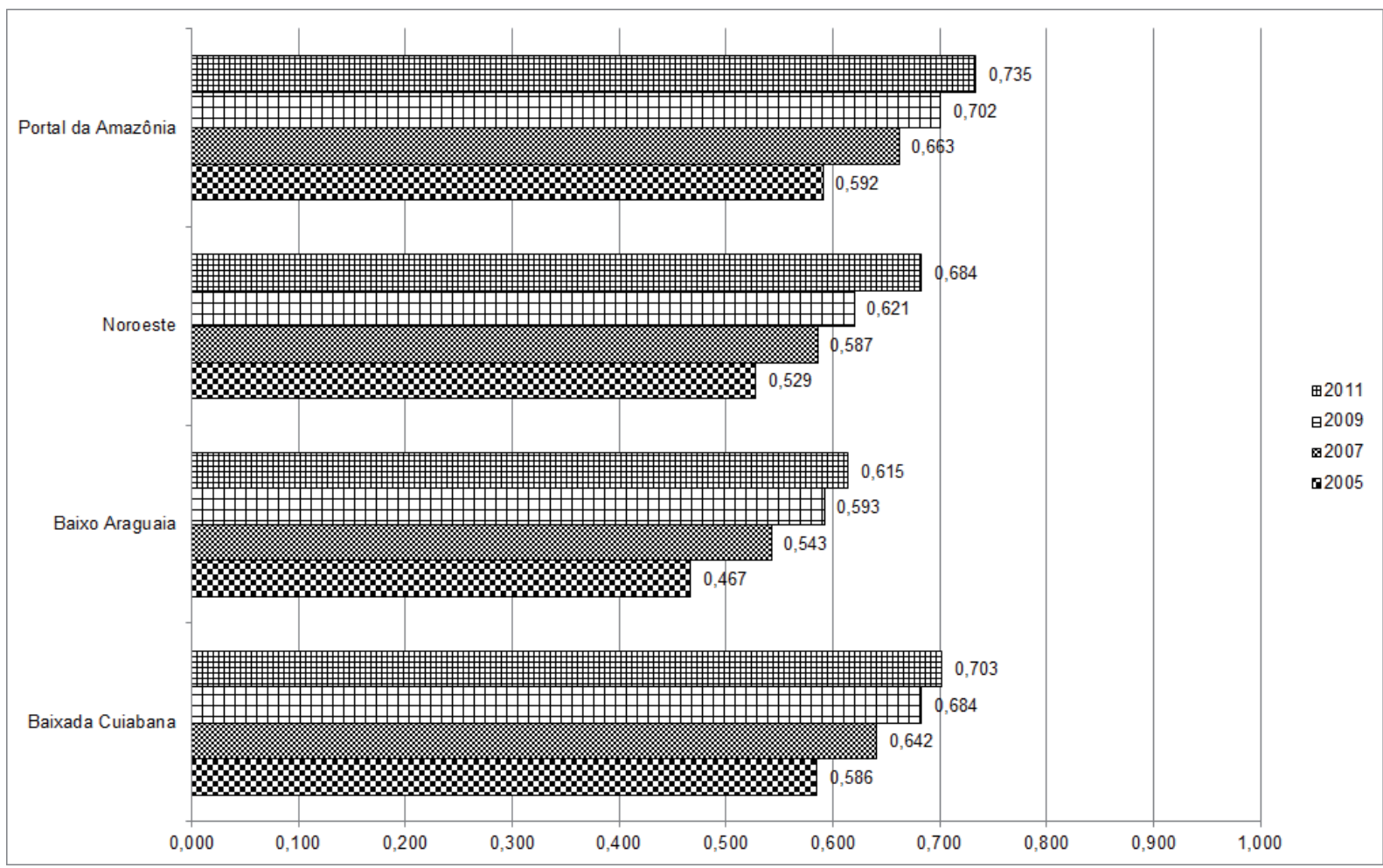

Fonte: adaptado de FIRJAN - IFDM (2014).

A média do IFDM-Educação melhorou contínua e crescentemente em todos os territórios nos períodos analisados. Em 2011, com exceção do Território Baixo Araguaia, os demais territórios conseguiram superar a linha de corte de 0,650 retratado como condições mínimas a serem atingidas por qualquer município que busca desenvolver-se.

A análise da condição de desenvolvimento considerando a média do IFDMEducação permitiu verificar que, em 2005, todos os territórios estavam na condição de “Desenvolvimento Regular" e, em 2011, todos se encontravam na condição de "Desenvolvimento Moderado". Tal condição foi galgada em momentos diferentes. Em 2007, os territórios Baixada Cuiabana e Portal da Amazônia foram os primeiros a alcançarem. Depois, em 2009, o território Noroeste a alcançou e, somente em 2011, o território Baixo Araguaia passou para essa condição.

Para se ter uma melhor visualização a respeito dos valores do IFDM-Educação, na Tabela 2 apresenta-se a variação percentual das médias desse índice.

Tabela 2 - Variação percentual das médias do IFDM-Educação dos Territórios da Cidadania do estado de Mato Grosso

\begin{tabular}{|l|c|c|c|c|}
\hline \multicolumn{1}{|c|}{ TERRITÓRIOS } & $\mathbf{2 0 0 5 - 2 0 0 7}$ & $\mathbf{2 0 0 7 - 2 0 0 9}$ & $\mathbf{2 0 0 9 - 2 0 1 1}$ & Acumulado 2005-2011 \\
\hline Baixada Cuiabana & $9,5 \%$ & $6,6 \%$ & $2,8 \%$ & $18,8 \%$ \\
\hline Baixo Araguaia & $16,2 \%$ & $9,1 \%$ & $3,8 \%$ & $29,1 \%$ \\
\hline Noroeste & $10,9 \%$ & $5,8 \%$ & $10,2 \%$ & $26,9 \%$ \\
\hline Portal da Amazônia & $12,0 \%$ & $5,9 \%$ & $4,7 \%$ & $22,6 \%$ \\
\hline
\end{tabular}

Fonte: Adaptado de FIRJAN - IFDM (2014).

Os avanços mais significativos para o IFDM-Educação foram de 2005 para 2007, quan- 
do todos os territórios tiveram as maiores variações percentuais, com destaque par o Território Baixo Araguaia. Ainda que ele não tenha atingido a linha de corte de 0,650 no acumulado de 2005 a 2011 (Gráfico 2), esse território foi o que apresentou o maior percentual acumulado chegando a uma variação positiva de $29,1 \%$. Também ressalta-se que, de 2007 a 2009, todos os territórios apresentaram valores positivos.

Por fim, o último indicador que compõe o IFDM avalia a saúde. A saúde é um importante indicador da qualidade de vida de populações, por isso qualquer política pública que pretende melhorar as condições de desenvolvimento deve abordá-la. Por isso, Fortes e Zoboli (2008, p. 200) enfatizam que as políticas públicas de saúde "têm como objetivos, entre outros, proporcionar um ótimo nível de saúde às pessoas, protegê-las dos riscos de adoecer e satisfazer as necessidades de saúde".

Para Duarte et al. (2002, p. 19), “os padrões de desigualdade em saúde variam no espaço e no tempo. Essas desigualdades podem ainda ser agravadas em função de determinantes demográficos e ambientais, acesso aos bens e serviços de saúde e de políticas sociais". Para Paim (2006, p. 15),

$\mathrm{A}$ atenção à saúde pode sofrer as influências do perfil epidemiológico da população, que depende, fundamentalmente, das condições e estilos de vida (modo de vida) e se expressa em necessidades (sofrimento, doença, agravos, riscos e ideais de saúde) e demandas por consultas, vacinas, informações, exames e hospitalizações.

Desse modo, no Gráfico 3 apresenta-se a média do IFDM-Saúde.

Gráfico 3 - Médias anuais do IFDM-Saúde dos

Territórios da Cidadania do estado de Mato Grosso

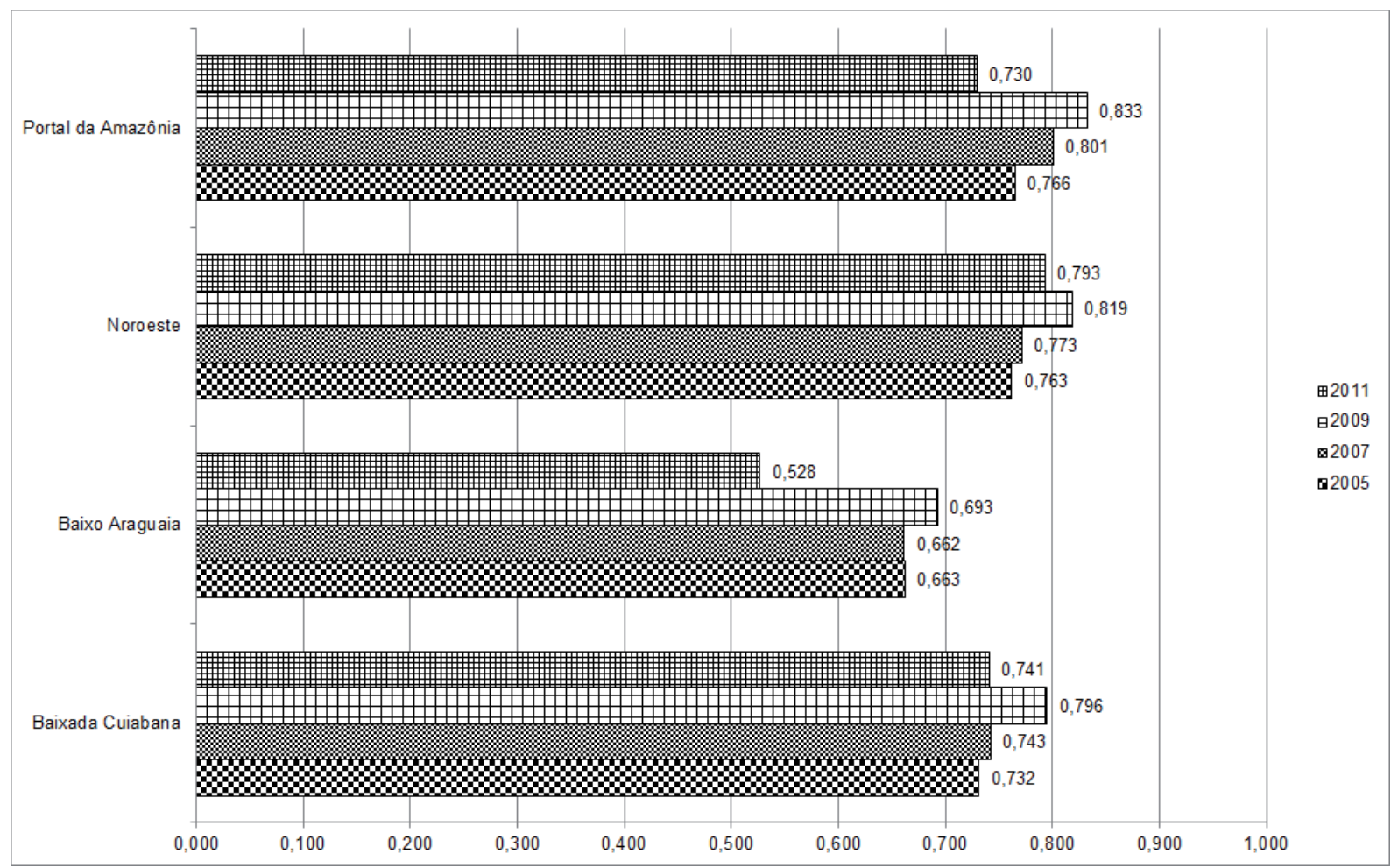

Fonte: adaptado de FIRJAN - IFDM (2014).

Ao analisar-se o Gráfico 3 em razão da média do IFDM-Saúde, percebe-se que os territórios Baixada Cuiabana, Noroeste e Portal da Amazônia apresentaram melhoras crescentes nos seus resultados até 2009. Já o
Território Baixo Araguaia teve leve queda de 2005 para 2007, conseguindo recuperar-se em 2009. Em 2011, todos os territórios apresentaram um decréscimo do índice, chamando atenção o Território Baixo Araguaia, cuja 
queda foi tão expressiva que ficou abaixo da linha de corte de 0,650 proposta.

A análise da condição de desenvolvimento considerando a média do IFDMSaúde apontou que, desde 2005, o Território Baixada Cuiabana vem classificando-se como de "Desenvolvimento Moderado". O Território Baixo Araguaia manteve-se na condição de "Desenvolvimento Moderado" de 2005 a 2009, retrocedendo para a condição de "Desenvolvimento Regular" em 2011. O Território Noroeste nos anos de 2005 e 2007 era classificado como de "Desenvolvimento Moderado", porém, em 2009, passou para a condição de "Alto Desenvolvimento" e retornou para a condição de "Desenvolvimento Moderado" em 2011. O Território Portal da Amazônia, em 2005, encontrava-se na condição de "Desenvolvimento Moderado" avançando de 2007 a 2009 para "Alto Desenvolvimento" e retrocedendo para a condição de "Desenvolvimento Moderado" em 2011. Na Tabela 3, apresenta-se a variação percentual das médias para o IFDM-Saúde.

Tabela 3 - Variação percentual das médias do IFDM-Saúde dos Territórios da Cidadania do estado de Mato Grosso

\begin{tabular}{|l|c|c|c|c|}
\hline \multicolumn{1}{|c|}{ TERRITÓRIOS } & $\mathbf{2 0 0 5 - 2 0 0 7}$ & $\mathbf{2 0 0 7 - 2 0 0 9}$ & $\mathbf{2 0 0 9 - 2 0 1 1}$ & Acumulado 2005-2011 \\
\hline Baixada Cuiabana & $1,4 \%$ & $7,2 \%$ & $-6,8 \%$ & $1,7 \%$ \\
\hline Baixo Araguaia & $-0,1 \%$ & $4,7 \%$ & $-23,9 \%$ & $-19,4 \%$ \\
\hline Noroeste & $1,3 \%$ & $6,0 \%$ & $-3,1 \%$ & $4,2 \%$ \\
\hline Portal da Amazônia & $4,6 \%$ & $4,0 \%$ & $-12,3 \%$ & $-3,7 \%$ \\
\hline
\end{tabular}

Fonte: Adaptado de FIRJAN - IFDM (2014).

Em relação à variação percentual das médias IFDM-Saúde, percebe-se que, para o Território Portal da Amazônia, ela foi decrescendo a cada um dos períodos analisados (2005 a 2007, 2007 a 2009, 2009 a 2011). Já para os Territórios Baixada Cuiabana, Baixo Araguaia e Noroeste, a variação percentual aumentou do período 2005 a 2007 ao período 2007 a 2009. Contudo, para o período 2009 a 2011, todos os territórios tiveram redução percentual de suas médias quando compara- das aos períodos anteriores. Isso indicou uma involução nesse período uma vez que todos os territórios ficaram com variação percentual negativa. No acumulado, o Território Noroeste se destacou com a maior variação percentual positiva acumulada desde 2005 $(4,2 \%)$.

Desse modo, para ter-se uma visão holística de cada Território da Cidadania do Estado de Mato Grosso, apresenta-se, no Gráfico 4, a média geral do IFDM. 
Gráfico 4 - Médias anuais do IFDM-Geral Territórios da Cidadania do estado de Mato Grosso

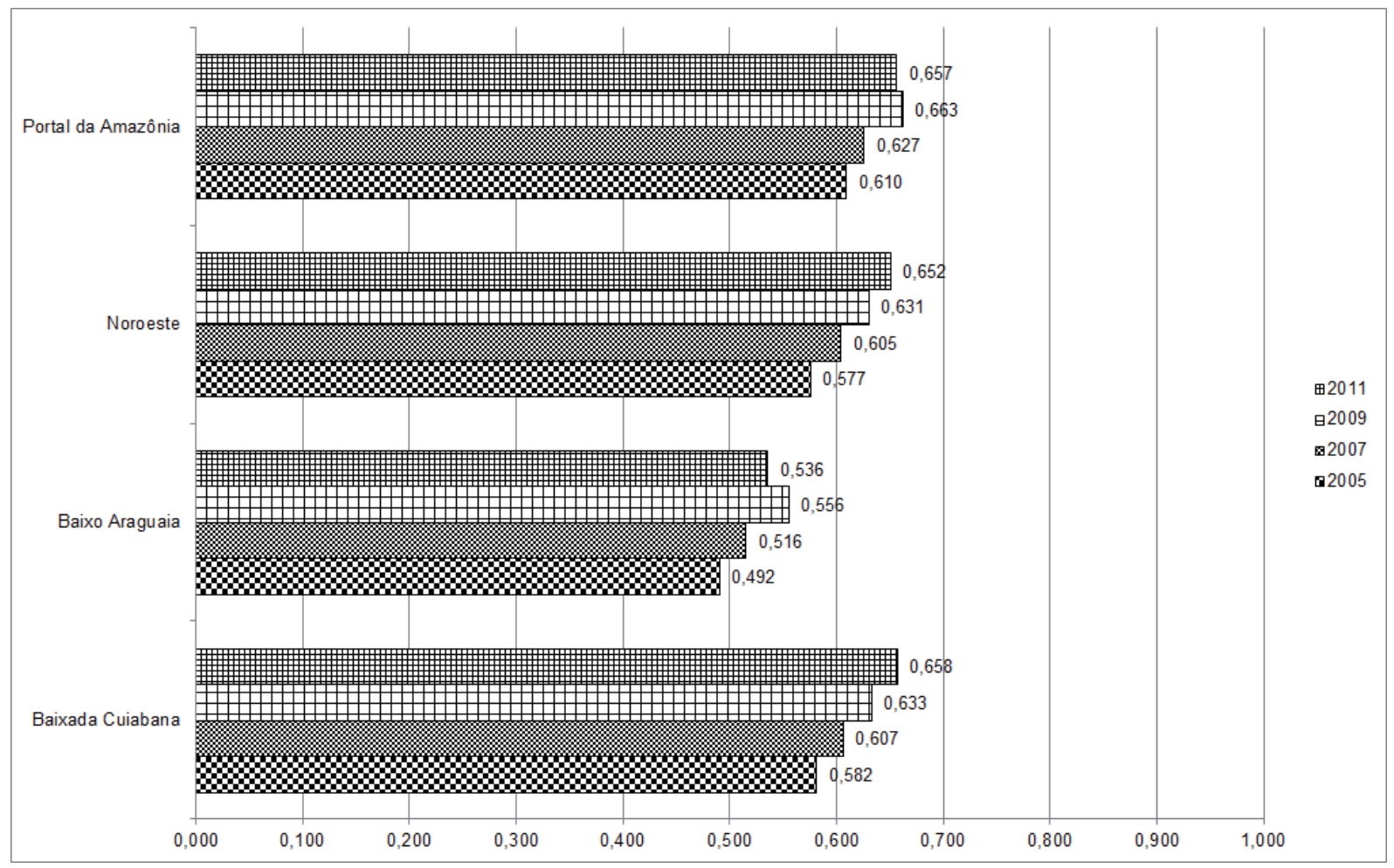

Fonte: adaptado de FIRJAN - IFDM (2014).

Pode-se considerar, ao analisar a média do IFDM-Geral dos territórios em estudo, que, apesar de todas as variações de cada um dos indicadores, houve um crescimento em todos os territórios nos referidos anos com um leve decréscimo para os Territórios do Baixo Araguaia e Portal da Amazônia apenas no ano de 2011. Contudo observa-se que o Território Baixo Araguaia ainda encontra-se com resultado inferior à linha de corte de 0,650 estipulado como adequado para este estudo. A classificação da condição de desenvolvimento considerando a média do IFDM-Geral para cada território permitiu notar que desde 2005 o Território Portal da Amazônia en- contra-se na condição de "Desenvolvimento Moderado". Os Territórios Baixada Cuiabana e Noroeste, em 2005, apresentaram-se na condição de "Desenvolvimento Regular" passando ambos, a partir de 2007, para a condição de "Desenvolvimento Moderado" mantendo-se nela até 2011. Por fim, o Território Baixo Araguaia mantém-se, desde 2005, na condição de "Desenvolvimento Regular". Esse resultado sinaliza para a necessidade de ações mais efetivas nas áreas analisadas por parte do Estado, incluindo a participação da sociedade civil organizada. Por fim, na Tabela 3, apresenta-se a variação percentual das médias para o IFDM-Geral.

Tabela 4 - Variação percentual das médias do IFDM-Geral dos Territórios da Cidadania do estado de Mato Grosso

\begin{tabular}{|l|c|c|c|c|}
\hline \multicolumn{1}{|c|}{ TERRITÓRIOS } & $\mathbf{2 0 0 5 - 2 0 0 7}$ & $\mathbf{2 0 0 7 - 2 0 0 9}$ & $\mathbf{2 0 0 9 - 2 0 1 1}$ & Acumulado 2005-2011 \\
\hline Baixada Cuiabana & $4,2 \%$ & $4,4 \%$ & $3,9 \%$ & $12,5 \%$ \\
\hline Baixo Araguaia & $4,9 \%$ & $7,8 \%$ & $-3,6 \%$ & $9,2 \%$ \\
\hline Noroeste & $4,9 \%$ & $4,3 \%$ & $5,5 \%$ & $14,7 \%$ \\
\hline Portal da Amazônia & $2,8 \%$ & $5,8 \%$ & $-0,9 \%$ & $7,6 \%$ \\
\hline
\end{tabular}

Fonte: Adaptado de FIRJAN - IFDM (2014). 
Mesmo que todos os territórios tenham apresentado no acumulado 2005-2011 uma variação percentual positiva das médias IFDMGeral, em que o Território Baixada Cuiabana chegou a $12,5 \%$, o Território Noroeste $14,7 \%$, o Território Baixo Araguaia 9,2\% e o Território Portal da Amazônia 7,6\%, os resultados apresentados devem ser relativizados tendo em vista a duração da política analisada, iniciada em 2008. Além disso, deve-se considerar que as mudanças nas áreas analisadas demoram a ser efetivadas. Dessa forma, pode-se dizer que os investimentos hoje realizados na educação, por exemplo, irão repercutir somente daqui a alguns anos na formação dos jovens, que influenciarão o mercado de trabalho, as formas de produção, geração de renda, permitindo um melhor padrão vida, menor incidência de problemas de saúde, dentre outras.

\section{CONSIDERAÇÕES FINAIS}

As políticas públicas territoriais no que se refere às áreas analisadas, Emprego e Renda; Educação; Saúde, são primordiais para a cidadania e para o desenvolvimento sustentável. Assim, pode-se considerar que não existem respostas prontas, mas certamente estão sendo lapidadas e, em um futuro próximo, espera-se que os resultados dessa política pública territorial venham a modificar e propiciar melhores condições de vida para estas populações.

Destaca-se que as três áreas analisadas são essenciais para que haja avanços na qualidade de vida e conduza a geração de ciclos virtuosos de crescimento e desenvolvimento, que devem ser articulados com avanços na conquista de direitos políticos e civis. Devese considerar, ainda, que outros indicadores podem apresentar resultados diferentes, dependendo dos requisitos avaliados e das ponderações dadas, porém, supõe-se que em perspectivas gerais não se haverá grandes desvios, ou seja, a situação dos municípios constituintes do programa Territórios da Cidadania no estado de Mato Grosso, realmente, necessita de uma assistência expressiva para modificar o quadro da cidadania, especialmente, relacionada às áreas de Emprego e Renda. Nas áreas de Educação e Saúde, notou-se que vem ocorrendo, desde 2005, um avanço crescente em todos os territórios.
A estrutura de gestão do programa Territórios da Cidadania aparenta ser um fator que contribui para essa modificação, pois o colegiado territorial composto por representantes das três esferas de governo e da sociedade em cada território tem atribuições que dão oportunidades (liberdades) aos cidadãos dos territórios abarcados a proporem ações não somente na esfera dos direitos sociais (Emprego e Renda; Educação; Saúde), mas também nas esferas dos direitos civis e políticos.

Pode-se considerar, também, que as práticas da reforma do Estado e da administração pública gerencial afetaram positivamente as áreas de Emprego e Renda, Educação e Saúde nos Territórios da Cidadania analisados, no sentido de reduzir a pobreza e a desigualdade social, ainda fortemente marcada nesses territórios e municípios.

\section{REFERÊNCIAS}

ABRUCIO, Fernando Luiz. Trajetória recente da gestão pública brasileira.: um balanço crítico e a renovação da agenda de reformas. Revista de Pública, Rio de Janeiro, Edição Especial Comemorativa, 1967-2007, p. 67-86, 2007.

ALCÂNTARA FILHO, José Luiz; SILVA, Márcio Gomes da; SILVA, Sandro Pereira. A abordagem territorial do desenvolvimento rural: análise a partir do território rural Baixo Jequitinhonha. In: Perspectivas em Políticas Públicas, Belo Horizonte, v. II, n. 3, p. 24-44, 2009. Disponível em: <http://www.revistappp.org/pdf/ artigo1ppp3.pdf>. Acesso em:10 ago. 2011.

BRESSER-PEREIRA, Luiz Carlos. Democracia, estado social e reforma gerencial. Revista de Administração de Empresas, 50(1), 112-116, 2010.

CAMPANTE, Rubens Goyatá. O patrimonialismo em Faoro e Weber e a Sociologia brasileira. DADOS, v. 46, n. 1, p. 153-193, 2003.

CARDOSO, Fernando Henrique. Apresentação. In: BRESSER-PEREIRA, Luiz Carlos; SPINK, Peter Kevin (Org.). Reforma do Estado e administração pública gerencial. Tradução Carolina Andrade. 7. ed. Rio de Janeiro: FGV, 2005. 316 p.

COSTA, Frederico Lustosa da. Condicionantes da reforma do Estado no Brasil. In: MARTINS, Paulo Emílio Matos; PIERANTI, Octavio Penna (Org.). Estado e gestão pública: visões do Brasil contemporâneo. Rio de Janeiro: Ed. da FGV, 2006. 339 p.

DEMO, Pedro. Política social, educação e cidadania. 12. ed. Campinas, SP: Papirus, 2010. 124 p.

DUARTE, Elisabeth Carmen; SCHNEIDER, Maria Cristina; SOUSA-PAES, Rômulo; RAMALHO, Walter Massa; SARDINHA, Luciana Maria Vasconcelos; SILVA JÚNIOR, Jarbas Barbosa da; CASTILLO-SALGADO, Carlos. Epidemiologia das desigualdades em saúde no Brasil: 
um estudo exploratório. 1. ed. Brasília: Organização Pan-Americana de Saúde - OPAS, 2002. 123 p.

FALEIROS, Vicente de Paula. A política social do estado capitalista: as funções da previdência e da assistência sociais. 6. ed. São Paulo: Cortez, 1991. 175 p.

FAVARETO, Arilson et. al. Políticas de desenvolvimento territorial rural no Brasil: avanços e desafios. Brasília: IICA, 2010. (Série Desenvolvimento Rural Sustentável, v.12). 220p.

FEDERAÇÃODAS INDÚSTRIAS DO ESTADO DO RIO DE JANEIRO (FIRJAN). Índice Firjan de Desenvolvimento Municipal-IFDM. Ano 5. Disponível em: <http://ifdm. firjan.org.br>. Acesso em: 14 jan. 2014.

Índice Firjan de Desenvolvimento MunicipalIFDM. Ano 4. Disponível em: <http:/ / ifdm.firjan.org. br>. Acesso em: 14 jan. 2014.

Índice Firjan de Desenvolvimento MunicipalIFDM. Ano 3. Disponível em: <http:/ /ifdm.firjan.org. br>. Acesso em: 14 jan. 2014.

Índice Firjan de Desenvolvimento MunicipalIFDM. Ano 1. Disponível em: <http:/ /ifdm.firjan.org. br>. Acesso em: 14 jan. 2014.

Índice de Desenvolvimento Municipal: nota metodológica. FIRJAN: Rio de Janeiro, 2009. Disponível em: <www.firjan.org.br/IFDM/download/IFDM_2009. pdf>. Acesso em: 15 set. 2011.

Índice Firjan de Desenvolvimento Municipal: nota metodológica. Rio de Janeiro: FIRJAN, 2008. Disponível em: <http:/ /ifdm.firjan.org.br>. Acesso em 14 de agosto de 2008.

FORTES, Paulo Antonio de Carvalho; ZOBOLI, Elma Lourdes Pavone. Ética na saúde pública. In: ROCHA, Aristides Almeida; CESAR, Chester Luiz Galvão (Ed.). Saúde pública: bases conceituais . São Paulo: Atheneu, 2008. 352 p.

GIDDENS, Anthony. A terceira via e seus críticos. Rio de Janeiro: Record, 2001. 190p.

GOHN, Maria da Glória. Os conselhos municipais e a gestão urbana. In: SANTOS JÚNIOR, Orlando Alves dos; RIBEIRO, Luiz César de Queiroz; AZEVEDO, Sérgio de (Org.). Governança democrática e poder local: a experiência dos conselhos municipais no Brasil. Rio de Janeiro: FASE/Revan, 2004. 286 p.

GREEN, Duncan. Da pobreza ao poder: como cidadãos ativos e estados efetivos podem mudar o mundo. São Paulo: Cortez, 2009. 648 p.

HABERMAS, Jürgen. Mudança estrutural na esfera públi$c a$ : investigações quanto a uma categoria da sociedade burguesa. Rio de Janeiro: Tempo Brasileiro, 2003. 398 p.

INSTITUTO BRASILEIRO DE GEOGRAFIA E ESTATÍSTICA (IBGE). Estados. [s.d.]. Disponível em: <http://www.ibge.gov.br/estadosat/perfil. php?sigla=mt>. Acesso em: 14 dez. 2014.

MUÑOZ AMATO, Pedro. Introdução à administração pública. Tradução Benedicto Silva. 2. ed. Rio de Janeiro: Fundação Getúlio Vargas, 1971. 301 p.

OLIVEIRA, Elias Rodrigues de; GUMARÃES JÚNIOR, Ernani de Souza; PEREIRA, José Roberto. Políticas públicas para qualificação profissional. In: PEREIRA,
José Roberto (Org.). Gestão social de políticas públicas. 1. ed. Lavras, MG: UFLA, 2010. 234 p.

OSBORNE, David; GAEBLER, Ted. Reinventando o governo: como o espírito empreendedor esta transformando o setor publico. 7. ed. Brasília: MH Comunicação, 1995. $436 \mathrm{p}$.

PAES DE PAULA, Ana. Paula. Por uma nova gestão pública: limites e potencialidades da experiência contemporânea. Rio de Janeiro: FGV, 2005. 204p.

PAIM, Jairnilson Silva. Atenção à saúde no Brasil. In: BRASIL. Ministério da Saúde. Saúde no Brasil: contribuições para a Agenda de Prioridades de Pesquisa. 2. ed. Brasília: Ministério da Saúde, 2006. 306 p.

PEREIRA, Benedito Dias. Mato Grosso: principais eixos viários e a modernização da agricultura. Cuiabá: Ed. UFMT, 2007. v. 1.55 p.

PEREIRA, José Matias. Curso de administração pública: foco nas instituições e ações governamentais. 3. ed. rev. e atual. São Paulo: Atlas, 2010a. xii, 263 p.

. Manual de gestão pública contemporânea. 3. ed. rev. e atual. São Paulo: Atlas, 2010b. 286 p.

PEREIRA, José Roberto. Reforma do Estado e Administração Pública em Minas Gerais: avanços e desafios. In: FERREIRA, Marco Aurélio Marques; EMMENDOERFER, Magnus Luiz; GAVA, Rodrigo (Org.). Administração pública, gestão social e economia solidária: avanços e desafios. 1. ed. Viçosa, MG: Universidade Federal de Viçosa, 2010. p. 113-128.

PORTAL DA CIDADANIA. Territórios da cidadania. [s.d.]. Disponível em: <http:/ / www.territoriosdacidadania.gov.br>. Acesso em: 11 dez. 2011.

PRZEWORSKI, Adam. Sobre o desenho do Estado: uma perspectiva agent $x$ principal. In: BRESSER-PEREIRA, Luiz Carlos; SPINK, Peter Kevin (Org.). Reforma do Estado e administração pública gerencial. Tradução Carolina Andrade. 7. ed. Rio de Janeiro: FGV, 2005. 316 p.

ROLNIK, Raquel; SOMEKH, Nadia. Governar as metrópoles: dilemas da recentralização. In: GONÇALVES, Maria Flora; BRANDÃO, Carlos Antônio; GALVÃO, Antônio Carlos (Org.). Regiões e cidades, cidades nas regiões: o desafio urbano-regional. São Paulo: Unesp, 2003.

SÁ PESTANA, Maria Inês Gomes de. Avaliação Educacional- o Sistema Nacional de Avaliação de Educação Básica. In: RICO, Elizabeth de Melo (Org.). Avaliação de políticas sociais: uma questão em debate. 6 . ed. São Paulo: Cortez, 2009. 155 p.

SILVA, Adailton da; SILVA, Josenilton da; ROSA, Waldemir. Juventude Negra e Educação Superior. In: CASTRO, Jorge Abrahão de; AQUINO, Luseni Maria C. de; ANDRADE, Carla Coelho de (Org.). Juventude e políticas sociais no Brasil. Brasília: Instituto de Pesquisa Econômica Aplicada - IPEA, 2009. 317 p.

SISTEMA DE INFORMAÇÕES TERRITORIAIS (SIT). Mapas: Território da Cidadania - Mato Grosso. 2009. Disponível em:<http://sit.mda.gov.br/territorio. php? menu=territorio\&base $=1 \&$ informe $=$ s\#>. Acesso em: 10 dez. 2011.

TENÓRIO, Fernando G. (Org.). Gestão social: metodologia, casos e práticas. 5. ed. Rio de Janeiro: FGV, 2007. 
VASCONCELOS, M. A. S. de. Fundamentos de economia. São Paulo: Saraiva, 2000.
WEBER, Max. Economia e sociedade. Brasília: EdUnB, 1999. v. 2. 584p. 